\title{
GLOBAL LİTERATÜRDE
}

ANTROPOMETRI VE PLASTIK CERRAHI BİRLIKKTELİĞI: 1975 VE 2017 YILLARI ARASINDAKI AKADEMIK YAYINLARIN BIBLIYOMETRIK ANALIZI

Ümran MUSLU*

Atıf/O: Muslu, Ümran (2018). Global Literatürde Antropometri Ve Plastik Cerrahi Birlikteliği: 1975 Ve 2017 Yıllan Arasındaki Akademik Yayınların Bibliyometrik Analizi, Hitit Üniversitesi Sosyal Bilimler Enstitüsü Dergisi, ANARSAN Sempozyumu Özel Sayısı, Ekim 2018, Cilt 11 Sayı 2, ss. 1321-1335

Özet: İnsan vücudunun farklı kısımlarının ölçümüyle insan yapısının ilişkilerini belirleme yöntemi antropometrinin konusudur. Plastik cerrahi bilim dalinda antropometri ile birçok çalışma alanı vardır. Bibliyometri, akademik literatürde belli alanda yayımlanan materyallerin detayl olarak incelenmesidir. Bibliyometrik çalsşmalar son yllarda artan bir ilgiyle karşılanmaktadır ancak plastik cerrahi alanında bibliyometrik çalışmalar akademik literatürde oldukça sinırlı sayıdadır. Bu çalışmada, akademik literatürdeki antropometri ve plastik cerrahi ortak yayınlarının bibliyometrik analizi yapılmaya çalışılmıştır. Çalışmamızda Web of Science (WoS) veri tabanlarinda (Web of Science Core Collection, SciELO Citation Index, Russian Science Citation Index) 1975 ve 2017 yıllar arasinda indekslenmiş antropometri ve plastik cerrahi ile ilgili yayinlar incelenmiştir. Akademik literatürün incelemesinde plastik cerrahi ve antropometri alanında toplam 132 yayın bulunmuştur. Gelişmiş ülkelerin yanında gelişmekte olan Türkiye'nin de literatüre katkıda dördüncü olarak sirasını alması önemlidir. Anahtar kelime bibliyometrik ăg analizinde ise "anthropometry" ana anahtar kelimesinin merkezde olduğu yonca paterni saptandı.

Anahtar Kelimeler: Antropometri, Plastik Cerrahi, Bibliyometri, Estetik Cerrahi

Makale Gelis Tarihi: / Makale Kabul Tarihi: 21.09.2018 / 16.10.2018

Bu makale Turnitin programinda kontrol edildi. This article was checked by Turnitin. Bu makale ANARSAN sempozyumunda sunulmuş aynı başlıklı bildirinin tam metnidir. * Dr. Öğr. Üyesi, Hitit Üniversitesi, Tip Fakültesi, Plastik Rekonstrüktif ve Estetik Cerrahi ABD, umrandr@hotmail.com 


\section{Collaboration Of Anthropometry And Plastic Surgery In Global Literature: A Bibliometric Analysis of The Academic Publications Between 1975 And 2017}

Citation/O: Muslu, Ümran (2018). Collaboration Of Anthropometry And Plastic Surgery In Global Literature: A Bibliometric Analysis of The Academic Publications Between 1975 And 2017, Hitit University Journal of Social Sciences Institute, Symposium of AAHA, Special Issue, Year 11, Volume 2, October, 2018, ss.. 1321-1335

Abstract: The main subject of anthropometry is to find methods to investigate the relationships of the human structure by the measurement of different parts of the human body. In the field of plastic surgery, there have many work fields with anthropometry. Bibliometrics is the detailed analysis of published materials in the academic literature. Bibliometric studies have received increasing interest in recent years, but bibliometric studies in the field of plastic surgery are limited in the academic literature. In this study, it was aimed to analyze co-publications of two scientific fields of anthropometry and plastic surgery in the literature. In our study, published articles on anthropometry and plastic surgery indexed between 1975 and 2017 in Web of Science (WoS) databases (Web of ScienceCore Collection, Scientific Index, and Russian ScienceCitation Index) were included. A total of 132 publications were found in the field of plastic surgery and anthropometry. Besides the developed countries, it was important that Turkey ranked fourth in contribution to the literature. Bibliometric analysis of keyword network revealed a "clover pattern" in which the keyword of "anthropometry" centered.

Keywords: Anthropometry, Plastic Surgery, Bibliometrics, Aesthetic Surgery

\section{GIRIŞ}

İnsan vücudunun farklı kısımlarının ölçümüyle insan yapısının ilişkilerini belirleme yöntemi antropometrinin konusudur (Özkoçak ve Özdemir, 2018). Antropometri antropolojinin bir bölümüdür. Tıbbın birçok alanında antropoloji çalışma alanı bulurken özellikle anatomi ön plana çıkmaktadır. Plastik cerrahi bilim dalıda anatomi ile içiçe olduğundan antropometri ile birçok çalışma alanı bulmuştur (Özkoçak ve ark. 2017; Özkoçak ve Özdemir, 2017; Özkoçak 2018; Özkoçak ve Özdemir, 2018).

Bibliyometri, akademik literatürde belli alanda yayımlanan materyallerin detaylı olarak incelenmesidir (Muslu 2018). İncelenen alandaki üretilen makaleler yazarlarına, yayın yıllarına, üretildikleri ülkelere, dergilere veya kurumlara göre istatistiksel olarak analiz edilebilir, literatürün o alandaki 
yayın ve atıf trendi bibliyometrik ve infometrik yöntemlerle önceden tahmin edilebilir (Ozsoy ve Demir, 2018). Bibliyometrik çalışmalar son yıllarda artan bir ilgiyle karşılanmaktadır ancak plastik cerrahi alanında bibliyometrik çalışmalar akademik literatürde oldukça sınırlı sayıdadır (Şenel ve Demir 2015; Senel ve Demir 2016; Şenel ve ark. 2017, Ozsoy ve Demir, 2018). Plastik cerrahi ve antropometri alanında yapılmış ve yayımlanmış herhangi bir çalışma bildiğimiz kadarıyla literatürde mevcut değildir. Bu çalışmada, akademik literatürdeki antropometri ve plastik cerrahi ortak yayınlarının bibliyometrik analizi yapılmaya çalışılmıştır.

\section{YÖNTEM}

Çalışmamız plastik cerrahi ve antropometri alanlarındaki akademik literatürün detaylı incelemesinin yapıldığı bibliyometrik bir çalışmadır.

\section{A. Verilerin toplanmas1}

Çalışmamızda Web of Science (WoS) veri tabanlarında (Web of ScienceCore Collection, SciELOCitation Index, Russian ScienceCitation Index ve ) 1975 ve 2017 yılları arasında indekslenmiş antropometri ve plastik cerrahi ile ilgili yayınlar incelenmiştir. Bahsi geçen yıllar arasındaki bütün yayınlar çalışmaya dahil edilmiş, 2018 yılında yayımlanmış bütün dokümanlar ise analizden çıkarıld1. Sorgu anahtar kelimeleri olarak "anthropometry" ve "plasticsurgery" kullanıldı.

\section{B. Veri analizi ve görüntüleme}

$\mathrm{Bu}$ çalışmadaki istatistiksel analizleri SPSS programı kullanarak gerçekleştirdik (Versiyon 22.0, SPSS Inc., Chicago, IL, ABD; Hitit Üniversitesi için lisanslanmış, Çorum, Turkey). Ülkelerin yayın yoğunluklarını göstermek için GunnMap uygulamasının ikinci sürümü kullanılmıştır (GunnMap n.d.). Ağ haritası için VOSviewer paket programı kullanılmıştır.

\section{BULGULAR}

Dünya çapındaki akademik literatürünün incelemesinde plastik cerrahi ve antropometri alanında toplam 132 yayın bulunmuştur. 


\section{A. Çalışma sahaları, dil ve makale türleri}

Antropometri ve plastik cerrahi alanında en çok yayın üretilen çalışma alanları cerrahi, fizyoloji, anatomi ve pediatri olarak bulunmuştur ( $\mathrm{n}=115,103,65$ ve 47 makale, Tablo 1).

Tablo 1. Antropometri ve plastik cerrahi alanındaki yayınların (1975-2017) çalışma alanlar1

\begin{tabular}{|l|c|c|}
\hline Araştırma alanları & Yayın sayısı* & \%* \\
\hline Cerrahi & 115 & 87,12 \\
\hline Fizyoloji & 103 & 78,03 \\
\hline Anatomi & 65 & 49,24 \\
\hline Pediatri & 47 & 35,61 \\
\hline Otorinolaringoloji & 38 & 28.79 \\
\hline Psikoloji & 27 & 20,45 \\
\hline Diş hekimliği / Oral cerrahi & 26 & 19,7 \\
\hline Radyoloji & 23 & 17,42 \\
\hline Antropoloji & 22 & 16,67 \\
\hline Solunum Sistemi & 21 & 15,91 \\
\hline Toplam & 172 & 100 \\
\hline
\end{tabular}

*Bazı yayınlar birden fazla kategoride indekslendiği için doküman sayı ve yüzdesi toplam sayı ve yüzdeden farklıdır

$\mathrm{Bu}$ alandaki literatürün \%94,7'si İngilizce idi. Diğer diller ise Korece, Portekizce, Rusça ve Fransızca olarak saptand1 (\%3,03, 2,27, 1,51 ve 0,76). Üretilen yayınların büyük bir çoğunluğu orijinal makale idi (\%94,7). Bunları tam metin bildiriler ve derlemeler izliyordu (\%12,12'sser oranla, Tablo 2). 
Tablo 2. Antropometri ve plastik cerrahi alanındaki yayınların doküman türlerine göre ayrımı

\begin{tabular}{|l|c|c|}
\hline Doküman türleri & Yayın sayısı* & \%* \\
\hline Orijinal makale & 125 & 94,7 \\
\hline Tam metin bildiri & 16 & 12,12 \\
\hline Özet bildiri & 4 & 3,03 \\
\hline Klinik çalışma & 3 & 2,27 \\
\hline Derleme & 16 & 12,12 \\
\hline Olgu raporu & 6 & 4,54 \\
\hline Editöre mektup & 5 & 3,79 \\
\hline Biyografi & 2 & 1,51 \\
\hline Diğer & 39 & 29,54 \\
\hline Toplam & $\mathbf{1 3 2}$ & $\mathbf{1 0 0}$ \\
\hline
\end{tabular}

*Bazı yayınlar birden fazla kategoride indekslendiği için doküman sayı ve yüzdesi toplam sayı ve yüzdeden farklıdır

\section{B. Yıllara göre yayın sayıları}

Yıllara göre yayın sayıları incelendiğinde yazılan yazılarda nicel olarak yıllara göre azalış ya da artış görülmemiş ve herhangi bir düzende saptanamamıştır. En çok yayın üretilen yıl 12 makale ile 2015 ve 2010 yıllarıdır (Şekil 1). 


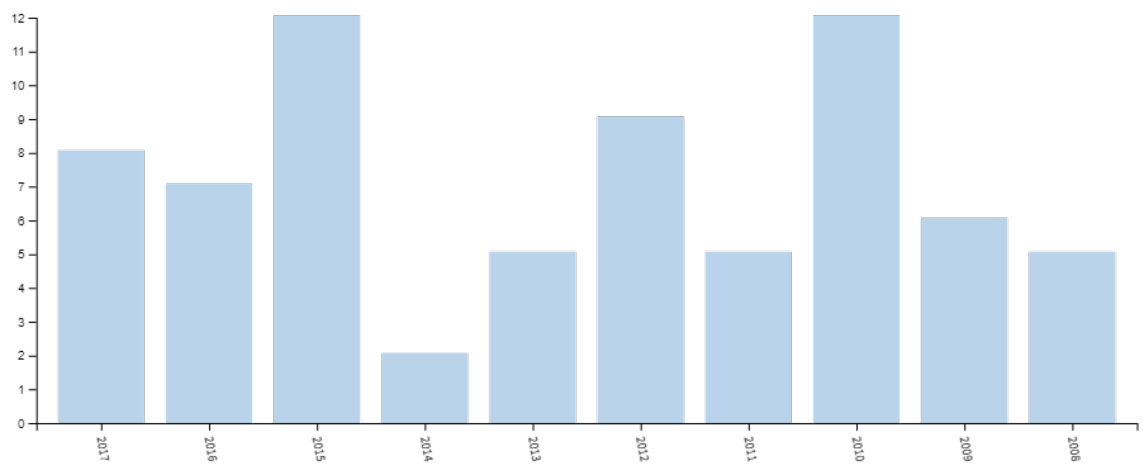

Şekil 1. Yayın sayılarının yıllara göre dağılımı

\section{C. Ülkelerin yayın üretkenlikleri}

Ülkeler yayımladıkları makale sayısına göre sıralandıklarında Amerika Birleşik Devletleri (ABD)37 makale ile ilk sırada geliyordu. Bu ülkeyi İngiltere, Çin ve Türkiye takip ediyordu ( $\mathrm{n}=11,9$, ve 8 yayın; Şekil 2).

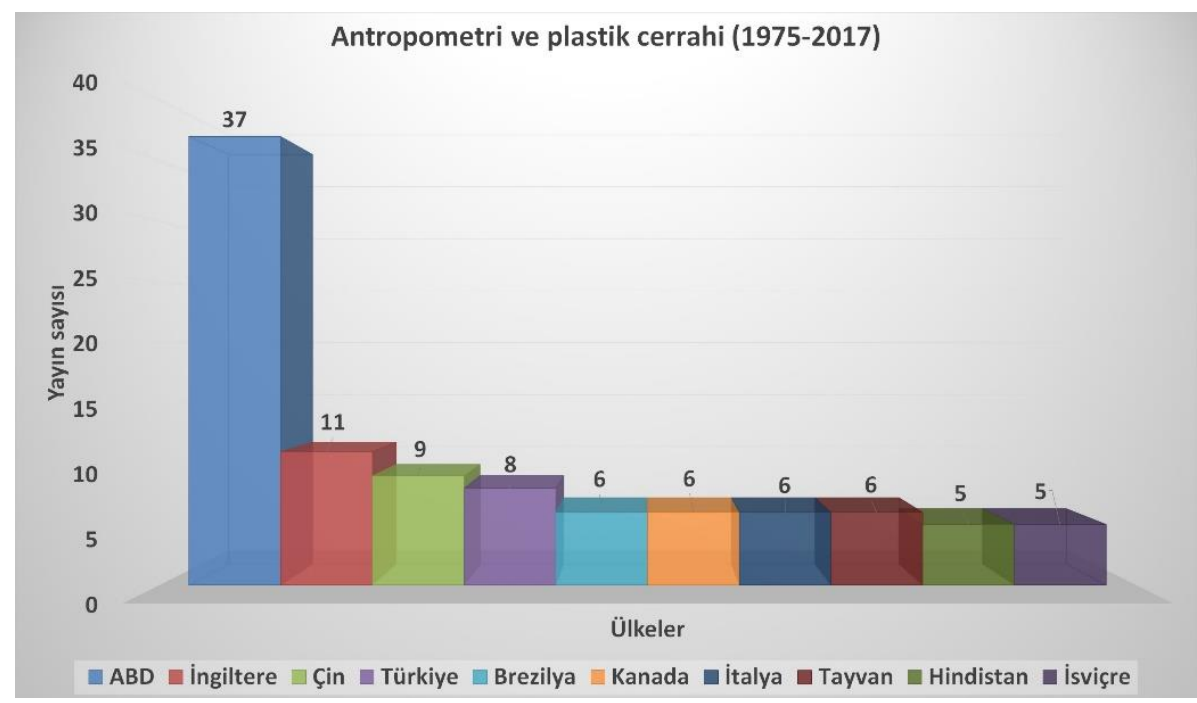

Şekil 2. En çok yayın üreten ilk 10 ülke 
Yayınlar, Afrika kıtası dışında bütün dünya kıtalarından üretilmişti (Şekil 3).

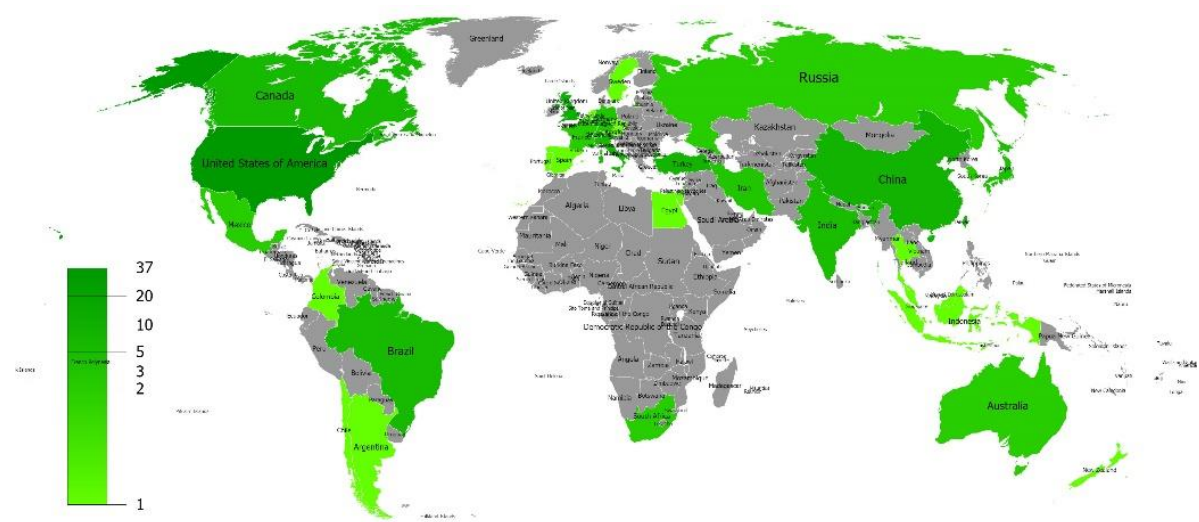

Şekil 3. Ülkelere göre Yayın sayılarının dağılımı

D. Yazarların, kurumların ve dergilerin üretkenlikleri ve konuyla ilgili toplantilar

Antropometrive plastik cerrahi alanında en çok yayın üreten yazarlar Farkas

L G,Flowers RS, Lubbers HT, Matthews F, Sforza C ( $n=4,3,3$, 3, 3 ve 3 yayin; Tablo 3) idi. 
Tablo 3. Antropometri ve plastik cerrahi alanında 1975 ve 2017 yılları arasında en çok yayın üreten on yazar

\begin{tabular}{|l|c|c|}
\hline Yazarlar & Yayın sayıs & $\%$ \\
\hline FARKAS L G & 4 & 3,03 \\
\hline FLOWERS RS & 3 & 2,27 \\
\hline LUBBERS HT & 3 & 2,27 \\
\hline MATTHEWS F & 3 & 2,27 \\
\hline SFORZA C & 3 & 2,27 \\
\hline CHANG CH & 2 & 1,51 \\
\hline CHANG PY & 2 & 1,51 \\
\hline CHEN JC & 2 & 1,51 \\
\hline CHEN PKT & 2 & 1,51 \\
\hline CHEN ZC & 2 & 1,51 \\
\hline
\end{tabular}

Antropometri ve plastik cerrahi alanında en çok makale yayınlayan ilk üç Dergi Journal Of Plastic Reconstructive And Aesthetic Surgery, Clinics In Plastic Surgery, Annals Of Plastic Surgery (n=19,12 ve 9 yayın; Tablo 4) idi. 
Tablo 4. Antropometri ve plastik cerrahi alanında 1975 ve 2017 yılları arasında en çok makale yayınlayan dergiler

\begin{tabular}{|l|c|c|}
\hline Dergi adi & $\begin{array}{c}\text { Makale } \\
\text { sayısı }\end{array}$ & \% \\
\hline $\begin{array}{l}\text { JOURNAL OF PLASTIC RECONSTRUCTIVE AND } \\
\text { AESTHETIC SURGERY }\end{array}$ & 19 & 14,39 \\
\hline CLINICS IN PLASTIC SURGERY & 12 & 9,09 \\
\hline ANNALS OF PLASTIC SURGERY & 9 & 6,82 \\
\hline JOURNAL OF CRANIOFACIAL SURGERY & 7 & 5,3 \\
\hline BRITISH JOURNAL OF PLASTIC SURGERY & 6 & 4,54 \\
\hline AESTHETIC PLASTIC SURGERY & 5 & 3,79 \\
\hline ARCHIVES OF PLASTIC SURGERY & 4 & 3,03 \\
\hline AESTHETIC SURGERY JOURNAL & 2 & 1,51 \\
\hline ARCHIVES OF FACIAL PLASTIC SURGERY & 2 & 1,51 \\
\hline $\begin{array}{l}\text { ARCHIVES OF OTOLARYNGOLOGY HEAD NECK } \\
\text { SURGERY }\end{array}$ & 2 & 1,51 \\
\hline
\end{tabular}

Antropometri ve plastik cerrahi alanındaki en çok yayın üreten ilk dört kurum Harvard Üniversitesi, Chang Gung Üniversitesi, Hasta Çocuklar Hastanesi, Toronto Üniversitesi ( $\mathrm{n}=7,5,5$ ve 5 yayın; Tablo 5 ) idi. 
Tablo 5. Antropometri ve plastik cerrahi alanındaki en çok yayın üreten kuruluşlar (1975-2017)

\begin{tabular}{|l|c|c|c|}
\hline Kurumlar & Ülke & $\begin{array}{c}\text { Yayın } \\
\text { sayısı }\end{array}$ & $\%$ \\
\hline Harvard Üniversitesi & ABD & 7 & 5,3 \\
\hline Chang Gung Üniversitesi & Tayvan & 5 & 3,79 \\
\hline Hasta Çocuklar Hastanesi & ABD & 5 & 3,79 \\
\hline Toronto Üniversitesi & Kanada & 5 & 3,79 \\
\hline Zürih Üniversitesi & İsviçre & 4 & 3,03 \\
\hline California Üniversitesi & ABD & 4 & 3,03 \\
\hline Londra Üniversitesi & İngiltere & 4 & 3,03 \\
\hline Sackler Tip Fakültesi & İsrail & 3 & 2,27 \\
\hline Tel Aviv Üniversitesi & İsrail & 3 & 2,27 \\
\hline Londra Üniversitesi Akademisi & İngiltere & 3 & 2,27 \\
\hline
\end{tabular}

$\mathrm{Bu}$ alanda üretilen bildirilerin hepsi tekli olarak kongre, seminer gibi bilimsel toplantılarda yayımlanmıştır.

\section{E. Atıf analizi}

Antropometri ve plastik cerrahi alanındaki literatürün H-indeksini 27 olarak tespit ettik. Çalışmamız yazıldığında anda bu alandaki yayınlar toplam 2203 defa atıf almıştı (Kendine yapılan atıflar hariç, 2161 defa). Her bir makalenin ortalama atıf değeri 16,69 defa olarak hesap ettik. 2016 yılı 212 atıf ile bu alanda en çok atıf alınan yıl olmuştur. Fertility and Sterility adlı dergide 1983 yılında yayımlanan "Significance of Testicular Size Measurement in Andrology.1. A New Orchiometer And Its Clinical-Application” isimli çalışma en çok atıf alan yayın olarak tespit edildi (Tablo 6). 
Tablo 6. Antropometri ve plastik cerrahi alanında 1975 ve 2017 yılları arasında en çok atıf alan on yayın

\begin{tabular}{|c|c|c|c|c|}
\hline Makale & Yazar(lar) & Dergi & $\begin{array}{l}\text { Topla } \\
\text { m atıf } \\
\text { sayıs1 }\end{array}$ & $\begin{array}{c}\text { Y1ll1k } \\
\text { ortalam } \\
\text { a atıf } \\
\text { sayıs1 }\end{array}$ \\
\hline $\begin{array}{l}\text { Significance of } \\
\text { Testicular Size } \\
\text { Measurement in } \\
\text { Andrology.1. A New } \\
\text { Orchiometer And Its } \\
\text { Clinical-Application }\end{array}$ & $\begin{array}{l}\text { TAKIHARA, } \\
\text { H; } \\
\text { SAKATOKU } \\
\text {, J; FUJII, } \\
\text { M; ve ark. }\end{array}$ & $\begin{array}{l}\text { FERTILITY } \\
\text { AND } \\
\text { STERILITY }\end{array}$ & 95 & 2,64 \\
\hline $\begin{array}{l}\text { Variation in Soft- } \\
\text { Tissue Thicknesses on } \\
\text { The Human Face and } \\
\text { Their Relation to } \\
\text { Craniometric } \\
\text { Dimensions }\end{array}$ & $\begin{array}{l}\text { Simpson, } \\
\mathrm{E} ; \\
\text { Henneberg, } \\
\mathrm{M}\end{array}$ & $\begin{array}{l}\text { AMERICAN } \\
\text { JOURNAL } \\
\text { OF } \\
\text { PHYSICAL } \\
\text { ANTHROPOL } \\
\text { OGY }\end{array}$ & 80 & 4,71 \\
\hline $\begin{array}{l}\text { Long-Term Outcome of } \\
\text { Facial Growth After } \\
\text { Functional } \\
\text { Encloscopic Sinus } \\
\text { Surgery }\end{array}$ & $\begin{array}{l}\text { Bothwell, } \\
\text { MR; } \\
\text { Piccirillo, } \\
\text { JF; Lusk, } \\
\text { RP; ve ark. }\end{array}$ & $\begin{array}{l}\text { OTOLARYNG } \\
\text { OLOGY- } \\
\text { HEAD AND } \\
\text { NECK } \\
\text { SURGERY }\end{array}$ & 76 & 4,47 \\
\hline $\begin{array}{l}\text { Bilateral Complete } \\
\text { Cleft-Lip and Nasal } \\
\text { Deformity- An } \\
\text { Anthropometric } \\
\text { Analysis of Staged to } \\
\text { Synchronous Repair }\end{array}$ & $\begin{array}{l}\text { MULLIKEN, } \\
\text { JB }\end{array}$ & $\begin{array}{l}\text { PLASTIC } \\
\text { AND } \\
\text { RECONSTRU } \\
\text { CTIVE } \\
\text { SURGERY }\end{array}$ & 72 & 3,00 \\
\hline $\begin{array}{l}\text { Precision and } \\
\text { Accuracy of the } 3 \mathrm{dmd} \\
\text { Photogrammetric } \\
\text { System in }\end{array}$ & $\begin{array}{l}\text { Luebbers, } \\
\text { Heinz-Theo; } \\
\text { Medinger, } \\
\text { Laurent; } \\
\text { Kruse, }\end{array}$ & $\begin{array}{l}\text { JOURNAL } \\
\text { OF } \\
\text { CRANIOFACI } \\
\text { AL } \\
\text { SURGERY }\end{array}$ & 70 & 7,78 \\
\hline
\end{tabular}




\begin{tabular}{|c|c|c|c|c|}
\hline $\begin{array}{l}\text { Craniomaxillofacial } \\
\text { Application }\end{array}$ & $\begin{array}{l}\text { Astrid; ve } \\
\text { ark. }\end{array}$ & & & \\
\hline $\begin{array}{l}\text { Superimposition and } \\
\text { reconstruction in } \\
\text { forensic facial } \\
\text { identification: A survey }\end{array}$ & $\begin{array}{l}\text { Aulsebrook, } \\
\text { WA; Iscan, } \\
\text { MY; } \\
\text { Slabbert, } \\
\text { JH; ve ark. }\end{array}$ & $\begin{array}{l}\text { FORENSIC } \\
\text { SCIENCE } \\
\text { INTERNATIO } \\
\text { NAL }\end{array}$ & 66 & 2,75 \\
\hline $\begin{array}{l}\text { Nonsurgical correction } \\
\text { of nasal deformity in } \\
\text { unilateral complete } \\
\text { cleft lip: A 6-year } \\
\text { follow-up }\end{array}$ & $\begin{array}{l}\text { Bennun, } \\
\text { RD; } \\
\text { Perandones } \\
\text {, C; } \\
\text { Sepliarsky, } \\
\text { VA; et al. }\end{array}$ & $\begin{array}{l}\text { PLASTIC } \\
\text { AND } \\
\text { RECONSTRU } \\
\text { CTIVE } \\
\text { SURGERY }\end{array}$ & 63 & 3,15 \\
\hline Brachydactyly & $\begin{array}{l}\text { Temtamy, } \\
\text { Samia A.; } \\
\text { Aglan, } \\
\text { Mona S. }\end{array}$ & $\begin{array}{l}\text { ORPHANET } \\
\text { JOURNAL } \\
\text { OF RARE } \\
\text { DISEASES }\end{array}$ & 60 & 5,45 \\
\hline $\begin{array}{l}\text { A new method for } \\
\text { determining bra size } \\
\text { and predicting } \\
\text { postaugmentation } \\
\text { breast size }\end{array}$ & Pechter, EA & $\begin{array}{l}\text { PLASTIC } \\
\text { AND } \\
\text { RECONSTRU } \\
\text { CTIVE } \\
\text { SURGERY }\end{array}$ & 60 & 2,86 \\
\hline $\begin{array}{l}\text { Concepts in aesthetic } \\
\text { breast dimensions: } \\
\text { Analysis of the ideal } \\
\text { breast }\end{array}$ & $\begin{array}{l}\text { Mallucci, } \\
\text { P.; } \\
\text { Branford, } \\
\text { O. A. }\end{array}$ & $\begin{array}{l}\text { JOURNAL } \\
\text { OF PLASTIC } \\
\text { RECONSTRU } \\
\text { CTIVE AND } \\
\text { AESTHETIC } \\
\text { SURGERY }\end{array}$ & 53 & 7,57 \\
\hline
\end{tabular}




\section{F. Anahtar kelime analizi}

Antropometri ve dermatoloji alanındaki en çok kullanılan anahtar kelimeler "anthropometry", "plasticsurgery" ve "rhinoplasty" olarak bulundu (Tablo 7).

Tablo 7. Antropometri ve plastik cerrahi alanındaki literatürde en çok kullanılan anahtar kelimeler

\begin{tabular}{|r|r|}
\hline \multicolumn{2}{|l|}{ Anahtar kelimeler (bağ kuvveti) } \\
\hline 1. Anthropometry (78) & 2. Plastic surgery (24) \\
\hline 3. Rhinoplasty (21) & 4. Cleft lip (18) \\
\hline 5. Comparative study (16) & 6. Craniofacial surgery (16) \\
\hline 7. Maxillofacial surgery (16) & 8. Breast anthropometry (13) \\
\hline 9. Breast ligaments (13) & 10. Mammaplasty (11) \\
\hline
\end{tabular}

Anahtar kelime bibliyometrik ağ analizinde ise "anthropometry" ana anahtar kelimesinin olduğu yonca paterni saptadık (Şekil 4).

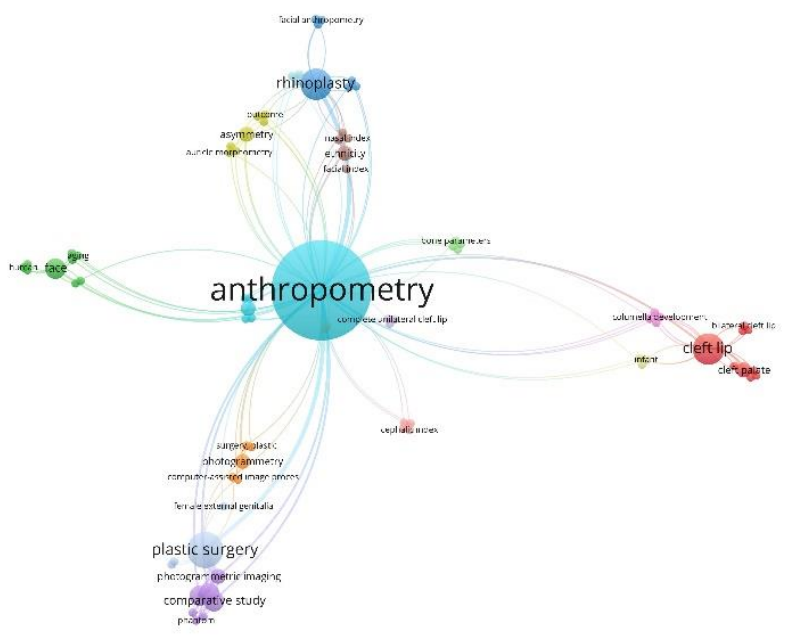

Şekil 4. Anahtar kelime bibliyometrik ağ analizi 


\section{SONUÇ VE TARTIŞMA}

Antropometri ve plastik cerrahi alanında en çok yayın üreten Amerika Birleşik Devletleri'ni, İngiltere, Çin ve Türkiye takip ediyordu. Ancak Afrika kıtasından hiç yayın yapılmamıştı. Gelişmiş ülkelerin yanında gelişmekte olan Türkiye' nin de dördüncü olarak sırasını alması önemlidir.

Anahtar kelimelerin network analizinde antropometri, plastik cerrahi ve rhinoplastynin ön plana çıkması ile bu kelimelerin daha yoğun işlendiğini göstermektedir.

En çok makale yayınlanan Journal of Plastic Reconstructive and Aesthetic Surgery dergisi 19 makale ile ilk sırayı alarak bu konuda diğer plastic cerrahi dergilerine öncülük etmekte idi.

Anahtar kelime bibliyometrik ağ analizinde ise "anthropometry" ana anahtar kelimesinin olduğu yonca paterni saptand1. Yonca yaprağinı oluşturan diğer anahtar kelimeler plastik cerrrahi, rhinoplasty ve cleftlip olarak bulundu.

Literatürde bu konuda yapılan bir bibliyometrik araştırmaya rastlanmamıştır. Antropometri ve plastik cerrahi alanında yaptığımız çalışmamıza network analizler ile görsel haritaların eklenmesi de bu bibliyometrik çalışmanın önemini daha da artırmıştır. 


\section{KAYNAKÇA}

GunnMap. n.d. “GunnMap 2.” Retrieved January 12, 2018 (http://lert.co.nz/map/).

Muslu, Ü. (2018) The Evolution of Breast Reduction Publications: A Bibliometric Analysis, Aesth Plast Surg. 42(3):679-691. doi: 10.1007/s00266-018-1080-7.

Ozsoy, Z. ve Demir, E. (2018) The Evolution of Bariatric Surgery Publications and Global Productivity: A Bibliometric Analysis, Obesity Surgery, 28(4):1117-29. https://doi.org/10.1007/s11695-017-2982-1

Ozsoy, Z. ve Demir, E. (2018) Which Bariatric Procedure Is the Most Popular in the World? A Bibliometric Comparison, Obesity Surgery, 28(8): 2339-52. https://doi.org/10.1007/s11695-018-3163-6

Özkoçak, V. Özdemir, F. (2017) Anadolu Erkeklerine Ait Yüz Ölçümleri Arasındaki İlişkinin İncelenmesi, Avrasya Sosyal ve Ekonomi Araştırmaları Dergisi, 4(11):176-186.

Özkoçak, V. (2018) Antropometric Techniques Used For Determining Aesthetic Anatomical and Anthropological Structure, Eurasian Academy of Sciences Eurasian Art \& Humanities Journal, 9: 30-38.

Özkoçak, V. Özdemir, F. (2018) Age-Related Changes in the External Noses of the Anatolian Men, Aesth Plast Surg 42(5):1336-42.

Özkoçak, V. Özdemir, F. (2018), Genç Yetişkin, Yetişkin Ve Yaşlı Anadolu Erkeklerinde Perioküler Antropometrik Ölçümler, The Journal of International Lingual, Social and Educational Sciences, 4(1): 78-85.

Şenel, E. and Demir E. 2015. "A Global Productivity and Bibliometric Analysis of Telemedicine and Teledermatology Publication Trends during 1980-2013.” Dermatologica Sinica 33(1).

Şenel, E. and Demir E. 2016. "An Update and Evaluation of Telemedicine and Teledermatology Publications for 2014.” SKINmed 14(2).

Şenel, E., Demir E., and Alkan RM. 2017. "Bibliometric Analysis on Global Behçet Disease Publications during 1980-2014: Is There a Silk Road in the Literature?" Journal of the European Academy of Dermatology and Venereology 31(3):51822.

Van Eck, NJ. and Waltman, L. (2010) Software survey: VOSviewer, a computer program for bibliometric mapping. Scientometrics, 84(2):523-538. 
